\title{
Reação de Híbridos de Pepino para Cultivo Protegido a Isolados de Corynespora cassiicola
}

\author{
Ricardo R. Oliveira, João B. Vida, Dauri J. Tessmann, \\ Bárbara M. Aguiar \& Marilda P. Caixeta \\ Departamento de Agronomia, Universidade Estadual de Maringá, CEP 87020-900, Maringá, PR, \\ e-mail: jbvida@uem.br
}

(Aceito para publicação em 21/11/2006)

Autor para correspondência: João Batista Vida

OLIVEIRA, R.R., VIDA, J.B., TESSMANN, D.J., AGUIAR, B.M. \& CAIXETA, M.P. Reação de híbridos de pepino para cultivo protegido a isolados de Corynespora cassiicola. Fitopatologia Brasileira 31:509-512. 2006.

\begin{abstract}
RESUMO
Corynespora cassiicola causa mancha alvo em folhas de diversas espécies de plantas, entre elas as cucurbitáceas. Este trabalho objetivou analisar a patogenicidade de 15 isolados de $C$. cassiicola originados de diferentes espécies hospedeiras a híbridos de pepino (Cucumis sativus) tipo ‘japonês', assim como avaliar a severidade da doença em condições de casa-devegetação. Verificou-se que somente três isolados originados de pepino e um isolado de abóbora foram capazes de infectar os quatro híbridos de pepino. Os híbridos Natsubayashi e Tsuyataro também foram infectados pelos dois isolados originados de soja e um originado de tomateiro. Quanto à severidade, os isolados de C. cassiicola originados de pepino mostraramse significativamente mais agressivos. Além disso, Tsuyataro mostrou-se mais suscetível dentre os híbridos testados. As diferenças na agressividade dos isolados de C. cassiicola sugerem maior adaptação dos isolados originados de pepino para os quatro híbridos, uma vez que estes foram significativamente mais agressivos do que os demais isolados.
\end{abstract}

Palavras-chave adicionais: Cucumis sativus, mancha alvo.

\begin{abstract}
Reaction of cucumber hybrids in protected cultivation against isolates of Corynespora cassiicola

Corynespora cassiicola causes target leaf spot on several plant hosts including cucurbits. The objectives of this study were to evaluate the pathogenicity of 15 isolates of $C$. cassiicola obtained from several hosts, to the Japanese cucumber hybrids (Cucumis sativus), as well as to evaluate the severity of the disease in greenhouse. It was observed that only three isolates from cucumber and one isolate from pumpkin were able to infect the four cucumber hybrids. Only 'Natsubayashi' and 'Tsuyataro' were infected by the two isolates from soybean and one isolate from tomato. The isolates from cucumber were significantly more aggressive than isolates from other hosts. Differences were also observed in susceptibility among the cucumber hybrids to C. cassiicola. 'Tsuyataro' was more susceptible than the other hybrids. Such differences in aggressiveness of the isolates and in the susceptibility of the hosts suggest a longer adaptation of C. cassiicola on cucurbits.
\end{abstract}

Additional keywords: Cucumis sativus, target leaf spot.

O fungo Corynespora cassiicola (Berk. \& M.A. Curtis) C.T. Wei é relatado causando doença a mais de 70 espécies de plantas distribuídas em diversos países de clima tropical e subtropical (Silva et al., 1995). Em razão da sua ampla gama de hospedeiros e vasta distribuição ao longo do mundo, Ellis (1971) descreveu C. cassiicola como sendo uma espécie cosmopolita e inespecífica. Antes do ano de 2000, C. cassiicola, agente etiológico da mancha alvo, era citado como um patógeno de pouca importância para a cultura do pepino, tanto em cultivo convencional quanto em ambiente protegido (Kurozawa \& Pavan, 1997). No entanto, nos últimos anos, a mancha alvo tem se tornado uma doença importante para os produtores de pepino tipo 'japonês' em estufas plásticas, devido a freqüentes epidemias desta

* Parte da Dissertação do primeiro autor. Universidade Estadual de Maringá PR. 2005. doença na região Norte do Estado do Paraná (Vida et al., 2004). Nesta modalidade de cultivo, Verzignassi et al. (2003) constataram que C. cassiicola em cultivos de pepino tipo 'japonês' causou manchas foliares, acarretando perdas de até $60 \%$ na produção e reduzindo a qualidade dos frutos.

Devido à grande importância que a mancha alvo tem assumido em cultivos de pepino tipo 'japonês' em ambiente protegido, estudos sobre o comportamento de isolados do patógeno teriam aplicação na busca de medidas de manejo da doença. Sendo assim, o objetivo deste trabalho foi verificar a reação de quatro híbridos de pepino a 15 isolados de $C$. cassiicola originados de diferentes espécies hospedeiras, como também a severidade da doença nesses híbridos.

$\mathrm{O}$ trabalho foi realizado em casa-de-vegetação e o delineamento experimental empregado foi inteiramente casualizado, com seis repetições, sendo cada unidade experimental constituída por uma planta. Foram avaliados 
quatro híbridos: hokushin, samurai, natsubayashi e tsuyataro. As mudas foram produzidas em bandejas de isopor com substrato comercial e posteriormente transferidas para sacos plásticos contendo substrato solo:areia na proporção 1:1 (V/ V), desinfestado com brometo de metila.

No ensaio experimental foram utilizados 15 isolados de C. cassiicola: IA, PB, JQ, 493AA, 777AA, LP05, LP02, GS01, GS02, LP01, RWB321, LP04, JMP220, CP03 e LP07. Os três primeiros foram originados de pepino, os dois seguintes de soja e os demais de abóbora, tomateiro, mamoeiro, assa-peixe (Vernonia sp.), alface, falso-boldo (Coleus barbatus Benth.), aceroleira (Malpighia glabra L.), lantana (Lantana camara L.), trapoeraba (Commelina benghalensis L.) e pimenta-longa (Piper hispidinervum C. DC.), respectivamente.

Todos os isolados partiram de culturas monospóricas e a multiplicação do inóculo foi realizada em placas-de-Petri em meio de cultivo BDA, incubadas por 15 dias a $24 \pm 2{ }^{\circ} \mathrm{C}$ em câmaras climatizadas do tipo B.O.D., sob luz fluorescente contínua. A suspensão de conídios foi ajustada para a concentração de $10^{4}$ conídios $/ \mathrm{ml}$. A inoculação das plantas procedeu-se pela atomização da suspensão de conídios sobre as folhas em ambas as faces, quando as plantas apresentavam duas folhas definitivas completamente expandidas. Em seguida, as plantas foram colocadas em câmara úmida por 48 horas, retornando logo após para as condições de casa-devegetação. Cinco dias após a inoculação, quando as lesões apresentaram desenvolvimento avançado $(0,5-1,0 \mathrm{~cm}$ de diâmetro), amostras de folhas sintomáticas foram coletadas e submetidas à câmara úmida por 48 horas, em condições de laboratório. Após este período, foram retiradas do centro das lesões estruturas produzidas pelo patógeno, transferindo-as para lâminas de microscopia e observado ao microscópio de luz. A reação foi considerada positiva (suscetível) em função da presença de sintomas da doença e de sinais do patógeno nos limbos foliares dos quatro híbridos de pepino testados.

Aqueles isolados de C. cassiicola que infectaram plantas dos híbridos de pepino no teste de patogenicidade foram utilizados para quantificar a reação de resistência/ suscetibilidade. Foi utilizada para a avaliação da severidade a escala Horsfall-Barratt modificada (Campbell \& Madden, 1990), com atribuição de notas: 0 = Ausência de sintomas,
$1=<1 \%$ de área foliar com sintomas (afs), $2=1$ a $3 \%$ de afs, $3=3,1$ a $6 \%$ de afs, $4=6,1$ a $12 \%$ de afs, $5=12,1$ a $25 \%$ de afs, $6=25,1$ a $50 \%$ de afs e $7=>50,1 \%$ de afs. Os resultados foram submetidos à análise de variância utilizando o programa SISVAR, versão 4.6 e as médias dos tratamentos comparadas pelo teste de agrupamento Scott-Knott a 5\% de significância.

Os resultados da reação dos quatro híbridos de pepino 'japonês' aos isolados de C. cassiicola estão expressos na Tabela 1. Somente sete dos 15 isolados testados originados de diferentes espécies hospedeiras foram capazes de infectar os híbridos de pepino. Os quatro híbridos foram suscetíveis aos isolados IA, PB, JQ (originados de pepino) e LP05 (originado de abóbora). Natsubayashi e tsuyataro, também foram suscetíveis aos isolados 493AA, 777AA (originados de soja) e LP02 (originado de tomateiro). Para esses três isolados, os híbridos hokushin e samurai apresentaram reação de imunidade. Para os oito demais isolados de $C$. cassiicola testados (GS01, JMP220, LP04, LP01, LP07, RWB321, CP03 e GS02), os quatro híbridos apresentaram reação de imunidade, não apresentando nenhum sintoma de mancha alvo.

Resultados neste sentido foram observados por Silva et al. (1998), onde 16 isolados de C. cassiicola, originados de seringueira, mamoeiro, mimosa e tomilho, diferiram quanto à patogenicidade, quando inoculados em plantas de berinjela. Os isolados de mamoeiro e nove dos isolados de seringueira não foram patogênicos à berinjela, os demais foram capazes de infectar esta espécie. Quando inoculados em feijão-de-corda, apenas os isolados originados de seringueira foram capazes de causar doença. Cutrim \& Silva (2003) relataram diferenças na patogenicidade entre dois isolados de C. cassiicola do tomateiro. Em caupi, o isolado 1 não foi patogênico e o isolado 2 o foi, já em soja, o contrário foi observado.

Quanto à severidade, as reações de maior suscetibilidade foram para os isolados originados de pepino. O híbrido tsuyataro foi o mais suscetível, com nível máximo de severidade da doença. Já o híbrido natsubayashi foi o mais resistente, com nota de severidade variando de 2,00 a 2,33. O híbrido hokushin apresentou alta suscetibilidade (nota 5,33) ao isolado PB e samurai ao isolado JQ (nota 5,17). Tsuyataro

TABELA 1 - Patogenicidade de isolados de Corynespora cassiicola originados de diferentes hospedeiros inoculados em quatro híbridos de pepino tipo ‘japonês' em casa de vegetação

\begin{tabular}{cccccccc}
\hline \hline \multicolumn{7}{c}{ Isolado/hospedeiro de origem/reação } \\
\hline \multirow{2}{*}{ Híbrido de Pepino } & IA & PB & JQ & LP05 & 493AA & 777AA & LP02 \\
& Pepino & Pepino & Pepino & Abóbora & Soja & Soja & Tomateiro \\
\hline Hokushin & + & + & + & + & - & - & - \\
Natsubayashi & + & + & + & + & + & + & + \\
Samurai & + & + & + & + & - & - & - \\
Tsuyataro & + & + & + & + & + & + & + \\
\hline
\end{tabular}

${ }^{1}(-)$ ausência de sintomas, $(+)$ presença de sintomas 


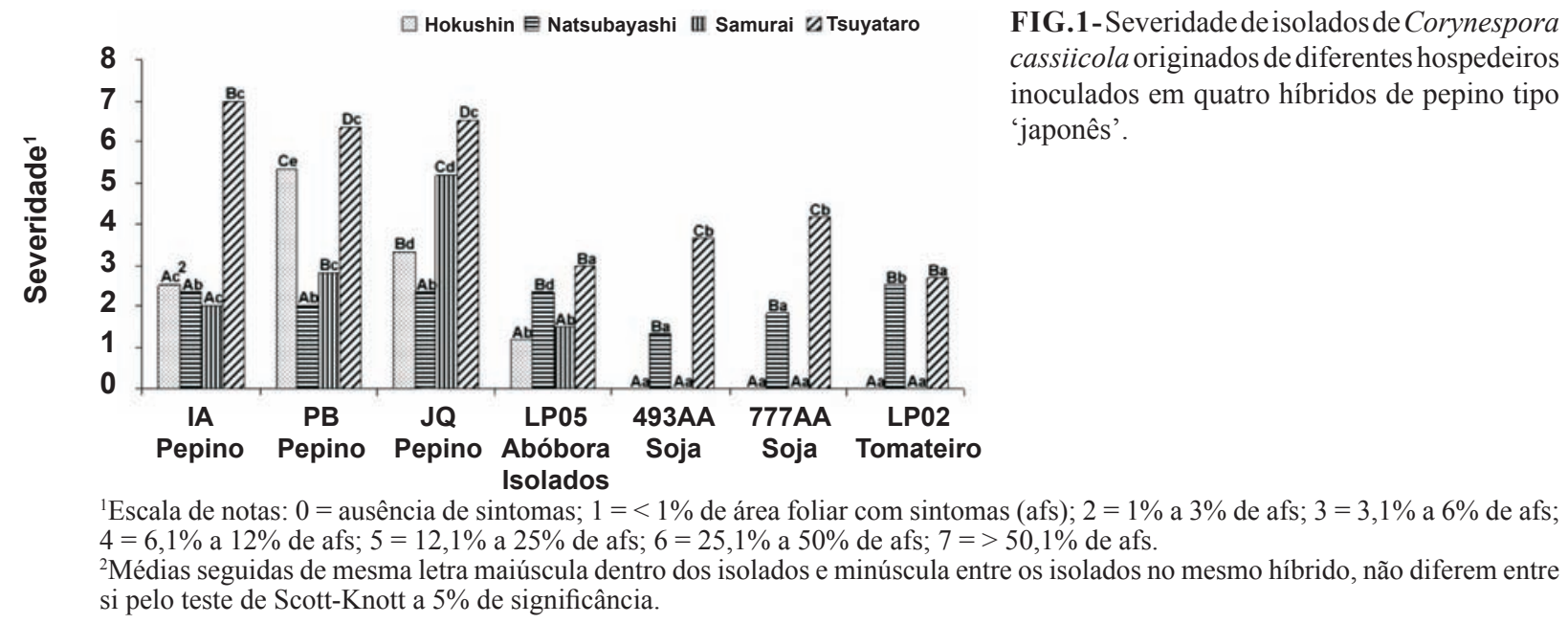

também apresentou reação de suscetibilidade relativamente alta (nota 4,17) ao isolado 777AA. Natsubayashi apresentou suscetibilidade, mas em muito baixo nível de reação, variando de 1,33 a 2,50. Dentre os híbridos, tsuyataro demonstrou ser o de maior suscetibilidade (Figura 1).

O período de incubação que envolveu os isolados originados de pepino (IA, PB e JQ) e o híbrido tsuyataro foi menor que 48 horas, já este período envolvendo os demais isolados foi maior que 72 horas. Segundo Bergamin \& Amorim (2002), o período de incubação é uma importante variável epidemiológica, pois a quantificação da doença baseia-se em sintomas visíveis.

Os isolados originados de pepino foram significativamente mais agressivos aos híbridos de pepino estudados, sugerindo maior adaptação para a espécie hospedeira, uma vez que foram mais agressivos que os demais isolados. O termo adaptação foi sugerido por Roim (2001), quando isolados originados de raízes de soja foram mais agressivos do que isolados originados de folhas, quando inoculados em raízes, sendo o contrário também observado. Ainda neste trabalho, os autores contataram diferenças significativas na agressividade de 17 isolados de C. cassiicola. Estas diferenças também foram observadas por Silva et al. (1998) entre 16 isolados de seringueira e três de mamoeiro, quando inoculados em três clones de seringueira.

Híbridos de pepino tipo 'japonês' podem apresentar diferenças quanto à resistência/suscetibilidade a isolados de C. cassiicola originados de diferentes espécies de plantas hospedeiras. Apesar dos híbridos natsubayashi e tsuyataro serem suscetíveis a maior número de isolados, o híbrido natsubayashi apresentou maior nível de resistência, contrapondo-se ao híbrido tsuyataro que apresentou nível máximo de suscetibilidade.

De acordo com os resultados obtidos pode-se afirmar que o cultivo de abóbora, soja e tomateiro adjacentes ao cultivo de pepino tipo 'japonês', desde que infectados por esse patógeno, podem servir como fonte de inóculo. Sugere-se ainda, que o cultivo do híbrido tsuyataro deve ser evitado em locais onde exista histórico de ocorrência de $C$. cassiicola. Além disso, diferenças na reação de resistência puderam ser observadas entre os quatro híbridos de pepino, quando inoculados com isolados de C. cassiicola originados de quatro diferentes espécies de plantas.

\section{AGRADECIMENTOS}

Os autores Ricardo R. Oliveira e Bárbara de M. Aguiar agradecem ao CNPq pela concessão de bolsa de estudos.

\section{REFERÊNCIAS BIBLIOGRÁFICAS}

BERGAMIN FILHO, A. \& AMORIM, L. Doenças com período de incubação variável em função da fenologia do hospedeiro. Fitopatologia Brasileira 27:561-565. 2003.

CAMPBELL, L.C. \& MADDEN, L.V. Introduction to Plant Disease Epidemiology. New York NY. John Wiley \& Sons. 1990.

CUTRIM, F.A. \& SILVA, G.S. Patogenicidade de Corynespora cassiicola a diferentes espécies de plantas. Fitopatologia Brasileira 28:193-194. 2003.

ELLIS, M.B. Dematiaceous Hyphomycetes. Kew. Commonwealth Mycological Institute.1971.

KUROZAWA, C. \& PAVAN, M.A. Doenças de cucurbitáceas. In: Kimati, H., Amorim, L., Bergamin Filho, A., Camargo, L.E.A. \& Rezende, J.A.M. (Eds.) Manual de Fitopatologia, Doenças das plantas cultivadas. Vol. 2. $3^{\text {a }}$ Ed. São Paulo SP. Ceres. 1997.

ROIM, F.L.B. Comportamento de cultivares e caracterização cultural, morfologia e patogênica de isolados de Corynespora cassiicola obtidos de soja [Glycine max (L.) Merrill]. 2001. Dissertação de Mestrado. Faculdade de Ciências Agrárias e Veterinárias, Universidade Estadual Paulista, Jaboticabal SP. 
SILVA, W.P.K., DEVERALL, B.J. \& LYON, B.R. Molecular, physiological and pathological characterization of Corynespora leaf spot fungi from rubber plantations in Sri Lanka. Plant Pathology 47:267-277. 1998.

SILVA, W.P.K., MULTANI, D.S., DEVERALL, B.J. \& LYON, B.R. RFLP and RAPD analyses in the identification and differentiation of isolates of the leaf spot fungus Corynespora cassiicola. Australian Journal of Botany 43:609-618. 1995.

VERZIGNASSI, J.R., VIDA, J.B. \& TESSMAM, D.J. Corynespora cassiicola causando epidemias de manchas foliares em pepino 'japonês' sob estufa no norte do Paraná. Fitopatologia Brasileira 28:570. 2003.

VIDA, J.B., OLIVEIRA, R.R., TESSMAM, D.J., VERZIGNASSI, J.R. \& COSTA, H. A agricultura protegida: PlasticulturaHortaliças-Manejo de doenças. In: Aguiar, L.R., Darezzo, R.J., Rozane, D.E., Aguilera, G.A.H. \& Silva, D.J.H. (Eds.) Cultivo em ambiente protegido - Histórico, Tecnologia e Perspectivas. Viçosa MG. 2004. pp. 225-240. 